\title{
Electrochemical Detection of Sugar-related Compounds Using Boron-doped Diamond Electrodes
}

\author{
Tomohisa Hayashi, $*$ Ikuo SAKurada, ${ }^{* *}$ Kensuke Honda, ${ }^{* * *}$ Shigeyasu MotohaShI, ${ }^{* \dagger}$ and \\ Kazuo UCHIKURA*
}

\author{
*School of Pharmacy, Nihon University, 7-7-1 Narashinodai, Funabashi, Chiba 274-8555, Japan \\ **Comet Co., 5-33-1 Kamiasou, Aso, Kawasaki, Kanagawa 215-5110, Japan \\ ***Department of Biological Science and Chemistry, Faculty of Science, Yamaguchi University, \\ 1677-1 Yoshida, Yamaguchi 753-8511 Japan
}

\begin{abstract}
Electrochemical detection of sugar-related compounds was conducted using a boron-doped diamond (BDD) electrode as a detector for flow-injection analysis (FIA). Sugar-related compounds oxidize at high applied potentials, for which the BDD electrode is suitable for electrochemical measurements. Conditions for an FIA system with a BDD detector were optimized, and the following detection limits were achieved for sugar-related compounds: monosaccharides, 25 - 100 pmol; sugar alcohols, $10 \mathrm{pmol}$; and oligosaccharides, $10 \mathrm{pmol}$. The detection limit for monosaccharide D-glucose (Glu) was $105 \mathrm{pmol}(S / N=3)$. A linear range was acquired from the detection limit to $50 \mathrm{nmol}$, and the relative standard deviation was $0.65 \%$ ( $20 \mathrm{nmol}, n=6)$. A high-performance liquid chromatography (HPLC) column was added to the system between the sample injector and the detector and detection limits to the picomole level were achieved, which is the same for the HPLC system and the FIA system. The electrochemical oxidation reaction of Glu was examined using cyclic voltammetry with the BDD detector. The reaction proved to be irreversible, and proceeded according to the following two-step mechanism: (1) application of a high potential $(2.00 \mathrm{~V} v s$. $\mathrm{Ag} / \mathrm{AgCl})$ to the electrode causes water to electrolyze on the electrode surface with the simultaneous generation of a hydroxyl radical on the surface, and (2) the hydroxyl radical indirectly oxidizes Glu. Thus, Glu can be detected by an increase in the oxidation current caused by reactions with hydroxy radicals.
\end{abstract}

(Received September 20, 2011; Accepted November 2, 2011; Published February 10, 2012)

\section{Introduction}

Sugar-related compounds are ubiquitous and of obvious importance in food and biogenic substances. Both direct and indirect methods for the detection of sugar-related compounds have been developed. Direct methods include electrochemical (EC) detection and evaporative light scattering detection (ELSD).

EC detection is performed by either an enzyme reaction or redox reaction at the electrode. ${ }^{1-9}$ For example, when EC detection of glucose is performed by an enzyme reaction, glucose oxidase is immobilized on an electrode where it oxidizes glucose, and the hydrogen peroxide produced can be monitored. A limitation of this method is that it is significantly dependent on the $\mathrm{pH}$ and the temperature, and the electrode/immobilizedenzyme system is prone to problems with long-term stability and reproducibility. In addition, the enzyme reaction detection method is highly successful for glucose; however, the simultaneous detection of glucose and other sugars is difficult. When EC detection is performed by an oxidization-reduction reaction at a metal electrode, the electrochemical oxidation of sugar at $\mathrm{Cu},{ }^{10-12} \mathrm{Ni},{ }^{12,13} \mathrm{Pt},{ }^{14,15}$ or $\mathrm{Au}^{14,15}$ electrodes generates a current that can be monitored. Sugar (typically glucose) can be

$\dagger$ To whom correspondence should be addressed.

E-mail: motohashi.shigeyasu@nihon-u.ac.jp detected to the picomole level using a Au electrode coupled with pulsed amperometric detection techniques. ${ }^{14,15}$ However, the limitations of this method are that the mobile phase (eluent) must be alkaline and the electrode surface must be cleaned between the measurements. Some methods that employ a glassy carbon electrode (GC) have been reported, although sugar is usually undetectable with a GC; therefore, the GC is modified with $\mathrm{Ni},{ }^{16,17} \mathrm{Co},{ }^{18}$ and $\mathrm{Cu}^{19}$ for the detection of sugar using the electrocatalytic activity of a specific metal.

ELSD is also widely used for the detection of sugar-related compounds, ${ }^{20}$ although the limitations of this method are its low selectivity and the fact that buffer solutions cannot be used. Indirect methods for the detection of sugar-related compounds include ultraviolet (UV) and fluorescence (FL) detection. Sugar-related compounds generally have no structure that absorbs UV. However, if a sugar derivative is prepared, then $\mathrm{UV}$ and FL absorption may be available. Arginine, ${ }^{21}$ 2-aminopyridine, ${ }^{22}$ and 2-cyaniacetamide ${ }^{23-25}$ have been used as typical derivatizing reagents. Derivatized sugar-related compounds can be detected to the picomole level; however, a limit of this method is that the derivatization reaction is complex and difficult to perform. Moreover, a detection method that can simultaneously detect all sugars in a sugar-related compound, including non-reducing sugars, is required. Ideally, such a method should be direct, easily performed, sensitive, and applicable to all sugars.

One promising development toward that end is the use of 
boron-doped diamond (BDD) electrodes. The superiority of BDD electrodes for electroanalysis is well known, due to their attractive material properties, which include a wide electrochemical potential window, very low voltammetric background current, high resistance to deactivation via fouling, and usability under extreme oxygen evolution conditions. These material properties are the impetus for our interest in studying and further developing BDD electrodes for electrochemical applications. ${ }^{26}$ The greatest advantage of BDD electrodes is that they can achieve a steady background at high applied potentials (approximately $2 \mathrm{~V} v s$. $\mathrm{Ag} / \mathrm{AgCl}$ ). Several applications of BDD electrodes for EC detection have been reported to date. Applications involving cyclic voltammetry (CV), flow-injection analysis (FIA) and high-performance liquid chromatography (HPLC) have been used to detect glucose, ${ }^{27}$ oxalic acid, ${ }^{28}$ uric acid, ${ }^{29}$ chlorophenol, ${ }^{30}$ and nucleic acid. ${ }^{31,32}$ In addition, BDD electrodes have even been used to treat wastewater. ${ }^{33-38}$ However, the BDD-electrode-based detection methods reported to date have not used a sufficiently wide electrical potential window, i.e., methods involving the application of high potentials have not yet been reported. Herein, we report the use of a BDD electrode with the application of high potentials $(2 \mathrm{~V} v s$. $\mathrm{Ag} / \mathrm{AgCl}$ ), coupled with FIA and HPLC, to detect sugars, such as saccharide and oligosaccharide in sugar-related compounds. In addition, the results of electrode reaction analysis by cyclic voltammetry are also reported.

\section{Experimental}

\section{Reagents and chemicals}

D-Glucose (Glu), D-galactose, D-xylose, D-fucose (Fuc), D-fructose (Fru), sorbitol (Sor), glycerol (Gly), ethylene glycol (Ety), maltose, sucrose, raffinose (Raf), $\alpha$-cyclodextrin, $\beta$-cyclodextrin, HPLC-grade acetonitrile, potassium dihydrogen phosphate $\left(\mathrm{KH}_{2} \mathrm{PO}_{4}\right)$, sodium dihydrogen phosphate $\left(\mathrm{NaH}_{2} \mathrm{PO}_{4}\right)$, phosphoric acid $\left(\mathrm{H}_{3} \mathrm{PO}_{4}\right)$, boric acid $\left(\mathrm{H}_{3} \mathrm{BO}_{4}\right)$, acetic acid $\left(\mathrm{CH}_{3} \mathrm{COOH}\right)$, ammonium acetate $\left(\mathrm{CH}_{3} \mathrm{COONH}_{4}\right)$, sulfuric acid $\left(\mathrm{H}_{2} \mathrm{SO}_{4}\right)$, sodium sulfate $\left(\mathrm{Na}_{2} \mathrm{SO}_{4}\right)$, nitric acid $\left(\mathrm{HNO}_{3}\right)$, and potassium nitrate $\left(\mathrm{KNO}_{3}\right)$ were purchased from Wako Pure Chemical Industries, Ltd. Xylitol, maltotriose, maltotetraose, maltopentaose, maltohexaose, and maltoheptaose were purchased from Tokyo Chemical Industry Co., Ltd. Milli-Q water (Millipore, $R \geq 18.2 \mathrm{M} \Omega \mathrm{cm}$ ) was used for all experiments. Samples were dissolved in either water or a carrier immediately before use.

\section{$B D D$-electrode detector}

The BDD electrode $(10 \times 20 \mathrm{~mm})$ used in this work was obtained from Associate Prof. Kensuke Honda. This electrode was a monopolar one-side coating. The BDD electrodes were prepared on $\mathrm{Nb}$ substrates by use of a microwave plasma-assisted chemical vapor deposition. The $\mathrm{B} / \mathrm{C}$ atomic ratio was $10^{4} \mathrm{ppm}$. The CVD conditions have been explained in detail elsewhere. ${ }^{39}$ Figure 1 shows a schematic of the detector formed from the electrode. A thin-layered amperometric flow cell was constructed with three electrodes: a BDD working electrode, an $\mathrm{Ag} / \mathrm{AgCl}$ reference electrode, and a stainless-steel tube counter electrode. A flow pathway $\left(3 \times 16 \times 0.2 \mathrm{~mm}^{3}\right)$ was made on the working electrode using a silicon rubber gasket as a spacer. Amperometric measurements were conducted using potentiostats (COMET-4003, Comet) connected to each electrode. Oxidation currents were monitored at a constant voltage during oxidation.

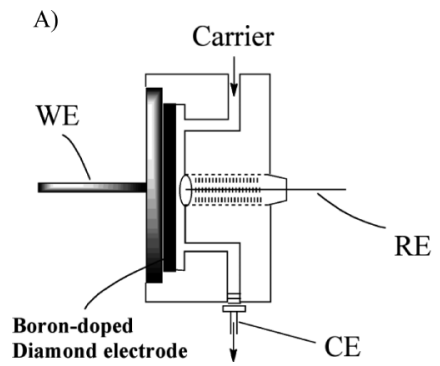

B)

Fig. 1 Schematic diagram of a boron-doped diamond (BDD) electrode detector. A) Side view, where CE, counter electrode; $\mathrm{RE}$, reference electrode; WE, working (BDD) electrode. B) Crosssectional view, where 1, working electrode (dashed line); 2, spacer; 3 , reference electrode; 4 , counter electrode; 5 , tube; 6 , effluent or eluent outlet.

\section{FIA and HPLC system}

FIA and HPLC systems were constructed and equipped with BDD-electrode detectors. The FIA system used a carrier buffer solution of $50-300 \mathrm{mM} \mathrm{KH} \mathrm{PO}_{4}(\mathrm{pH} 2.0-10.0)$ and an applied potential of $0-2.90 \mathrm{~V} \mathrm{vs}$. $\mathrm{Ag} / \mathrm{AgCl}$. The temperature of the detector was set to $20-60^{\circ} \mathrm{C}$ using a temperature-controlled bath. Samples were injected with a sample injector. The HPLC system added to this basic setup an HPLC column between the sample injector and the detector. When the eluent was water, a reagent solution was added via a three-outlet attachment cock between the column and the detector. $\mathrm{KH}_{2} \mathrm{PO}_{4}$ buffer solution was added to the eluent from the column. The system was equipped with HPLC pumps (LC-10A, Shimadzu Corp. and uf-7002P, Flom Co.), a 20- $\mu \mathrm{L}$ sample loop injector (Rheodyne), a BDD detector (fabricated as described above), a temperature-controlled bath (Column Oven 505, Flom Co.), and a data-processing equipment (CR-5A Chromatopac, Shimadzu). The system used two HPLC columns: SUGAR SH 1821 (300 mm $\times 8 \mathrm{~mm}$ i.d.; Shodex) or Develosil RP-Aquous-AR $(250 \mathrm{~mm} \times 4.6 \mathrm{~mm}$ i.d.; Nomura Chemical Co.). All experiments were performed at room temperature $\left(25^{\circ} \mathrm{C}\right)$.

\section{Cyclic voltammetry measurements}

CV measurements were conducted using a potentiostat/galvanostat (HABF501, Hokuto Denko Corp.) and a recorder (WX4420XY, Watanabe Instruments). The measurement system employed three electrodes: a BDD working electrode, an $\mathrm{Ag} / \mathrm{AgCl}$ reference electrode, and a stainless-steel tube counter electrode. Glu was dissolved in a $100 \mathrm{mM} \mathrm{KH}_{2} \mathrm{PO}_{4}$ buffer solution to prepare $1-10 \mathrm{mM}$ samples. The electrode surface was washed before each measurement by electrolysis for $5 \mathrm{~min}$ at an oxidation potential of $2.60 \mathrm{~V}$ in $0.5 \%$ hydrochloric acid solution. Samples were measured at a scan rate of $100 \mathrm{mV} / \mathrm{s}$ and all $\mathrm{CV}$ measurements were performed at room temperature $\left(25^{\circ} \mathrm{C}\right)$.

\section{Results and Discussion}

\section{Optimization of detection conditions}

The following six detection conditions for the BDD-electrode FIA system were examined: carrier buffer solution, buffer-solution $\mathrm{pH}$, ion strength, flow rate, applied oxidation potential, and detector temperature. The detection indicators were assumed to be oxidation (peak area) and background currents. For samples, Glu from aldose, Fru from ketose, 
Sor from sugar alcohol, and Gly from alcohol were used. Carrier buffer solution. Carrier buffer solutions were examined to determine the relative performance of 10 salts and reagents commonly used as buffers; $50 \mathrm{mM}$ solutions ( $\mathrm{pH}$ uncontrolled) of $\mathrm{KH}_{2} \mathrm{PO}_{4}, \mathrm{NaH}_{2} \mathrm{PO}_{4}, \mathrm{H}_{3} \mathrm{PO}_{4}, \mathrm{H}_{3} \mathrm{BO}_{4}, \mathrm{CH}_{3} \mathrm{COOH}, \mathrm{CH}_{3} \mathrm{COONH}_{4}$, $\mathrm{H}_{2} \mathrm{SO}_{4}, \mathrm{Na}_{2} \mathrm{SO}_{4}, \mathrm{HNO}_{3}$, and $\mathrm{KNO}_{3}$ were prepared. The effects of these buffers as carrier solutions for samples of Glu are summarized in Table 1. Three solutions performed unsatisfactorily; $\mathrm{H}_{3} \mathrm{BO}_{4}$ and $\mathrm{CH}_{3} \mathrm{COOH}$ failed to give a steady baseline in the presence of an increasing background current, and $\mathrm{CH}_{3} \mathrm{COONH}_{4}$ similarly failed to give a detectable peak even in the presence of a steady background current. The other seven solutions performed satisfactorily, exhibiting good baseline stability and detection reproducibility. Solutions of the three phosphoric-acid-based compounds, $\mathrm{KH}_{2} \mathrm{PO}_{4}, \mathrm{NaH}_{2} \mathrm{PO}_{4}$, and

Table 1 Effect of carrier solution on the peak area and the background current

\begin{tabular}{lcc}
\hline Carrier $(50 \mathrm{mM})$ & Peak area $\left(\times 10^{5}\right)$ & Back ground current $/ \mu \mathrm{A}$ \\
\hline $\mathrm{KH}_{2} \mathrm{PO}_{4}$ & 16.4 & 6 \\
$\mathrm{NaH}_{2} \mathrm{PO}_{4}$ & 15.6 & 7 \\
$\mathrm{H}_{3} \mathrm{PO}_{4}$ & 9.9 & 6 \\
$\mathrm{H}_{3} \mathrm{BO}_{4}$ & $-\mathrm{a}$ & - \\
$\mathrm{CH}_{3} \mathrm{COOH}$ & - & - \\
$\mathrm{CH}_{3} \mathrm{COONH}$ & - & 12 \\
$\mathrm{H}_{2} \mathrm{SO}_{4}$ & 4.2 & 5 \\
$\mathrm{Na}_{2} \mathrm{SO}_{4}$ & 11.5 & 9 \\
$\mathrm{HNO}_{3}$ & 7.3 & 7 \\
$\mathrm{KNO}_{3}$ & 9.1 & 11 \\
\hline
\end{tabular}

Sample: D-glucose $(2 \mathrm{nmol})$.

a. Not detected.
$\mathrm{H}_{3} \mathrm{PO}_{4}$, exhibited the highest sensitivity. Therefore, the $\mathrm{KH}_{2} \mathrm{PO}_{4}$ buffer solution was selected as the optimal carrier.

Applied oxidation potential. The optimum applied oxidation potential for the detection of sugar-related compounds was examined by measuring hydrodynamic voltammograms over the range of $0.0-2.10 \mathrm{~V} v s$. $\mathrm{Ag} / \mathrm{AgCl}$. Figure 2(A) shows plots of the current (peak area) as a function of the applied oxidation potential (the resulting plot is a hydrodynamic voltammogram). Four samples were measured: Glu, Fru, Sor, and Gly. The peak area and background current were both significantly affected by the potential. For all samples, the peak area in the range $0.0-1.50 \mathrm{~V}$ vs. $\mathrm{Ag} / \mathrm{AgCl}$ was undetectable and increased with increasing potential in the range of $1.60-2.00 \mathrm{~V} v s . \mathrm{Ag} / \mathrm{AgCl}$. The peak area reached a maximum with increasing potential for all samples (for Glu and Fru at $2.00 \mathrm{~V} v s$. $\mathrm{Ag} / \mathrm{AgCl}$, and for Sor and Gly at $2.05 \mathrm{~V}$ vs. $\mathrm{Ag} / \mathrm{AgCl}$ ), after which it decreased. The difference between the maximum values for Glu/Fru and Sor/Gly are not discussed here, but will be investigated in the near future. Thus, for all samples, the peak area decreased with increasing potential above $2.05 \mathrm{~V}$ vs. $\mathrm{Ag} / \mathrm{AgCl}$, i.e., the peak shape tails and detection becomes unstable. The background current in the range of $1.50-2.00 \mathrm{~V} v s . \mathrm{Ag} / \mathrm{AgCl}$ increased gradually, and then increased suddenly above $2.00 \mathrm{~V} v s$. $\mathrm{Ag} / \mathrm{AgCl}$. Therefore, according to the relative signal/noise $(S / N)$ ratio, the range $1.9-2.0 \mathrm{~V} v s . \mathrm{Ag} / \mathrm{AgCl}$ was determined to be the optimal applied oxidation potential range.

Detector temperature. The BDD-electrode detector temperature was examined within the range of $20-60^{\circ} \mathrm{C}$. Figure $2(\mathrm{C})$ shows that the peak area increased with increasing temperature in the range of $20-50^{\circ} \mathrm{C}$, and remained constant above $50^{\circ} \mathrm{C}$, while the background current remained almost constant in the range of $20-40^{\circ} \mathrm{C}$ and increased above $40^{\circ} \mathrm{C}$. Therefore, based on the relative $S / N$ ratio, the range $20-40^{\circ} \mathrm{C}$ proved to be the
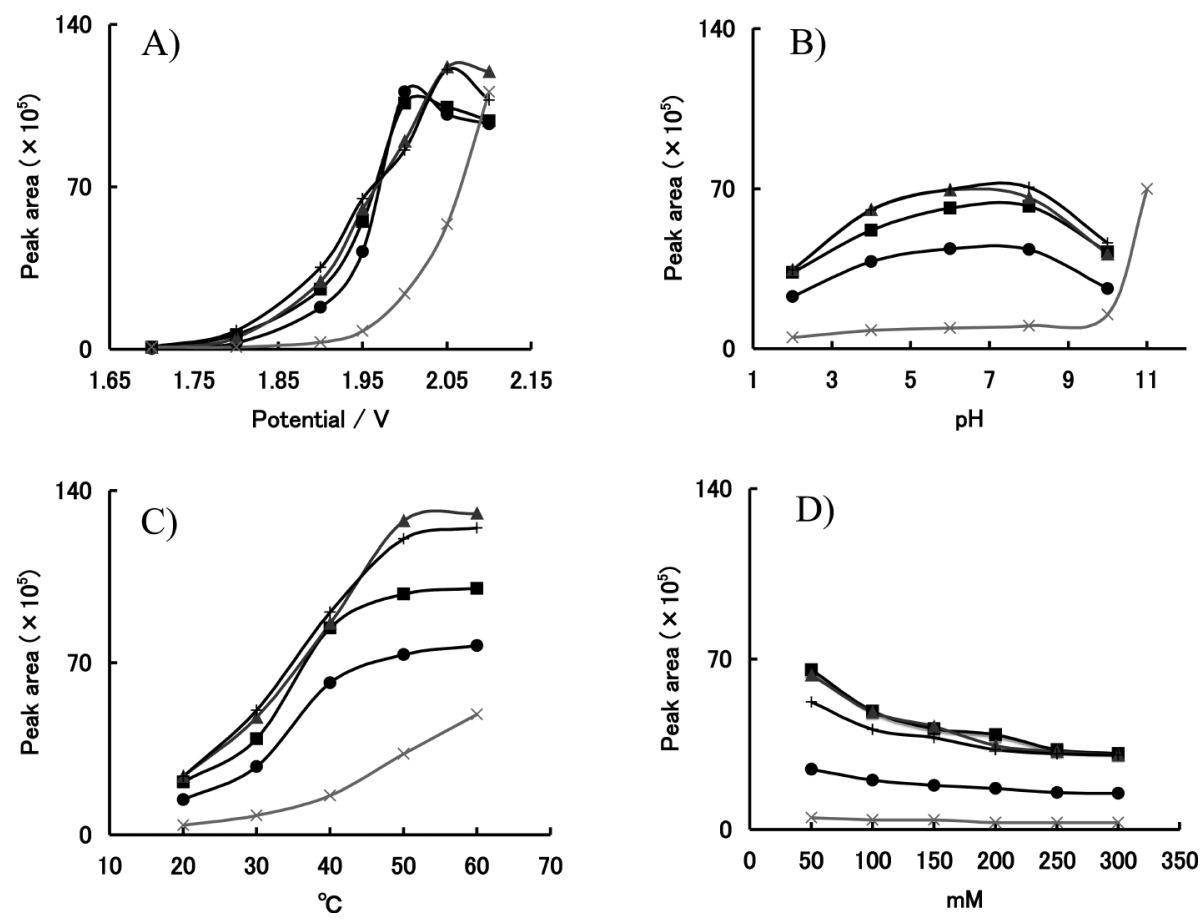

Fig. 2 Current (peak area) as a function of various detection conditions for four sugar-related compounds, which indicates the effects of the detection conditions on the peak area and the background current. A) Applied oxidation potential (the resulting plot is a hydrodynamic voltammogram). B) Buffer solution pH. C) Detector temperature. D) Buffer solution ion strength. Symbols: $\bullet$, D-glucose; 口, D-fructose; $\mathbf{\Lambda}$, sorbitol; +, glycerol; $\times$, background current. 
optimal detector temperature range.

$\mathrm{pH}$ and ion strength of buffer solution. The $\mathrm{pH}$ of the $\mathrm{KH}_{2} \mathrm{PO}_{4}$ buffer solution was examined within the $\mathrm{pH}$ range of $2.0-11.0$. Figure 2(B) shows that the peak area increased in the $\mathrm{pH}$ range of 2.0-6.0, remained almost constant for $\mathrm{pH} 6.0-8.0$, and decreased in the $\mathrm{pH}$ range of $8.0-10.0$. The background current increased slightly in the $\mathrm{pH}$ range of $2.0-10.0$, and was unsteady above pH 11.0. The acidic range was more advantageous than the alkaline range; therefore, from the relative $S / N$ ratio, the $\mathrm{pH}$ range of $4.0-6.0$ was determined as the optimal buffer $\mathrm{pH}$ range. The ion strength of the $\mathrm{KH}_{2} \mathrm{PO}_{4}$ buffer solution was examined in the range of 50-300 mM. Figure 2(D) shows that the peak area and background current decreased only slightly with increasing ion strength. The background current was almost constant, which indicates that the ion strengths in this range do not significantly influence detection. Thus, the ion strengths in this range were optimal for the detection of sugar-related compounds.

Detection limits for sugar-related compounds

The detection limits for the following sugar-related compounds were investigated: monosaccharides, sugar alcohols,

Table 2 Detection limit and relative standard deviation of sugar-related compounds

\begin{tabular}{lcc}
\hline \multicolumn{1}{c}{ Compound } & $\begin{array}{c}\text { Detection limit/ } \\
\text { pmol }(s / n=3)\end{array}$ & $\begin{array}{c}\text { RSD }, \% \\
(20 \mathrm{nmol}, n=10)\end{array}$ \\
\hline Glucose & 105.1 & 0.65 \\
Galactose & 101.2 & 1.25 \\
Xylose & 96.1 & 0.69 \\
Fucose & 52.9 & 2.41 \\
Fructose & 25.8 & 1.60 \\
Sorbitol & 10.2 & 2.00 \\
Xylitol & 11.7 & 2.60 \\
Glycerol & 12.7 & 1.68 \\
Ethylene glycol & 10.8 & 1.29 \\
Maltose & 11.2 & 1.45 \\
Sucrose & 10.0 & 1.23 \\
Lactose & 10.7 & 1.45 \\
Raffinose & 9.9 & 0.95 \\
Maltohexaose $(\mathrm{G6})$ & 10.0 & 1.50 \\
Maltoheptaose $(\mathrm{G} 7)$ & 7.5 & 1.70 \\
Cyclomaltohexaose $(\alpha$-CD) & 9.8 & 0.90 \\
Cyclomaltoheptaose $(\beta$-CD) & 5.0 & 0.93 \\
\hline
\end{tabular}

FIA conditions: carrier solution, $100 \mathrm{mM} \mathrm{KH}_{2} \mathrm{PO}_{4}(\mathrm{pH} 4.5$ ); flow rate, $0.5 \mathrm{~mL} / \mathrm{min}$; applied potential, $1.95 \mathrm{~V}$ vs. $\mathrm{Ag} / \mathrm{AgCl}$; detector temperature, $30^{\circ} \mathrm{C}$. disaccharides, trisaccharides, and oligosaccharides. The

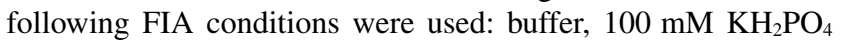
( $\mathrm{pH} 4.5$ ); flow rate, $0.5 \mathrm{~mL} / \mathrm{min}$; applied potential, $1.95 \mathrm{~V} v s$. $\mathrm{Ag} / \mathrm{AgCl}$; detector temperature, $30.0^{\circ} \mathrm{C}$. The measured detection limits are listed in Table 2. The Glu, D-galactose, and D-xylose monosaccharides were detected to 105.1, 101.2, and $96.1 \mathrm{pmol}$, respectively $(S / N=3)$. The deoxysugar fucose was detected to $52.9 \mathrm{pmol}(S / N=3)$ and the ketose Fru was detected to $25.8 \mathrm{pmol}(S / N=3)$. The sugar alcohols Sor and xylitol were detected to 10.2 and $11.7 \mathrm{pmol}$, respectively $(S / N=3)$ and Gly and Ety were detected down to 12.7 and 10.8 pmol, respectively $(S / N=3)$. The disaccharides maltose, sucrose, and lactose were detected to $11.2,10.0$, and $10.7 \mathrm{pmol}$, respectively $(S / N=3)$. The trisaccharide Raf was detected to $9.9 \mathrm{pmol}(S / N=3)$. The oligosaccharides maltohexaose, maltoheptaose, cyclomaltohexaose ( $\alpha$-cyclodextrin), and cyclomaltoheptaose $(\beta$-cyclodextrin) were detected to $10.0,7.5,9.8$, and $5.0 \mathrm{pmol}$, respectively $(S / N=3)$. Linear ranges were acquired for all measured compounds from the detection limits to $50 \mathrm{nmol}\left(R^{2}=>0.993\right)$, and the reproducibility measured over 10 repetitive injections and expressed as the relative standard deviation (RSD) was $<2.60 \%$. Thus, the sugar-related compounds were detected with sufficient sensitivity, especially ketose, sugar alcohols, and oligosaccharides. Although these compounds are expected to be more easily oxidized than monosaccharides on a BDD electrode surface, the detailed mechanisms are not discussed here, but further BDD electrode surface studies will be reported in the near future. Satisfactory detection limits for sugar-related compounds were successfully achieved using the FIA system equipped with a BDD electrode.

The relationship between the sugar-molecule number and the detection sensitivity was investigated. Maltooligosaccharides, in which Glu is connected with a linear $\alpha(1-4)$ linkage were used, and 500 pmol of maltooligosaccharides were prepared: Glu (G1), maltose (G2), maltotriose (G3), maltotetraose (G4), maltopentaose (G5), maltohexaose (G6), and maltoheptaose (G7). Figure 3 shows that the peak area increased with respect to the number of glucose molecules, which suggests that the detection sensitivity increases with the number of sugar molecules.

\section{Liquid chromatography with BDD-electrodes}

The FIA system equipped with a BDD detector was sufficiently sensitive to detect sugar-related compounds such as monosaccharides, alcohols, and oligosaccharides. This section examines the detection performance of a HPLC system in which a HPLC column is inserted between the sample injector and the column of the FIA system and the same measurement conditions
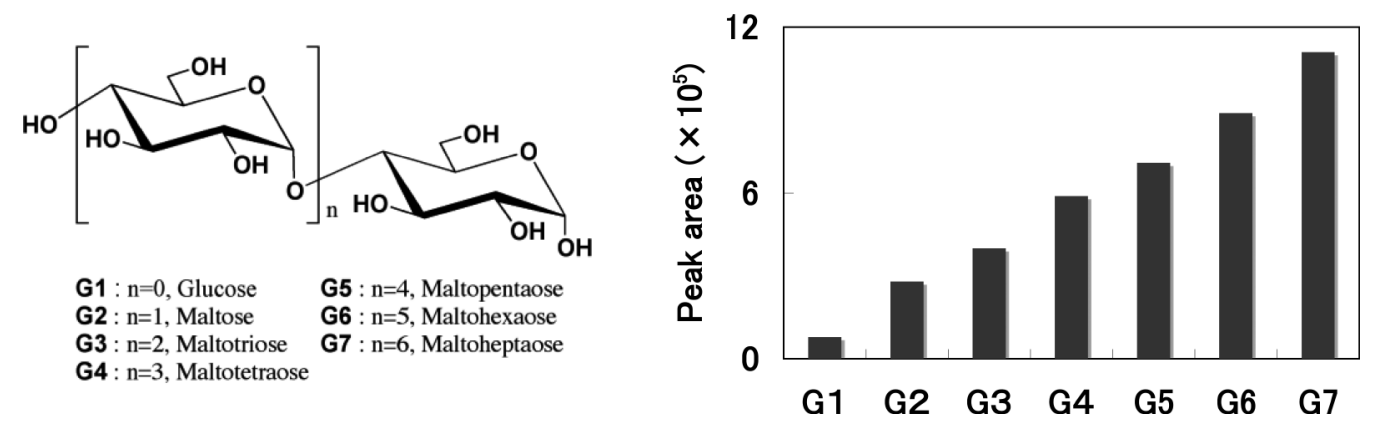

Fig. 3 Structure of maltooligosaccharides (left) and associated FIA-system detection sensitivity (right). 
as that for the FIA system were used.

Saccharides and alcohols. HPLC experiments were performed using saccharides and alcohols: Glu, Fuc, Raf, Gly, and Ety. The following HPLC conditions were used: eluent, water; eluent flow rate, $0.9 \mathrm{~mL} / \mathrm{min}$; buffer, $300 \mathrm{mM} \mathrm{KH}_{2} \mathrm{PO}_{4}$ (pH 4.5); buffer flow rate, $0.3 \mathrm{~mL} / \mathrm{min}$ (there is a purpose to give electroconductive to eluent from the column because this used water to separate); HPLC column, Shodex SUGAR SH 1821 at

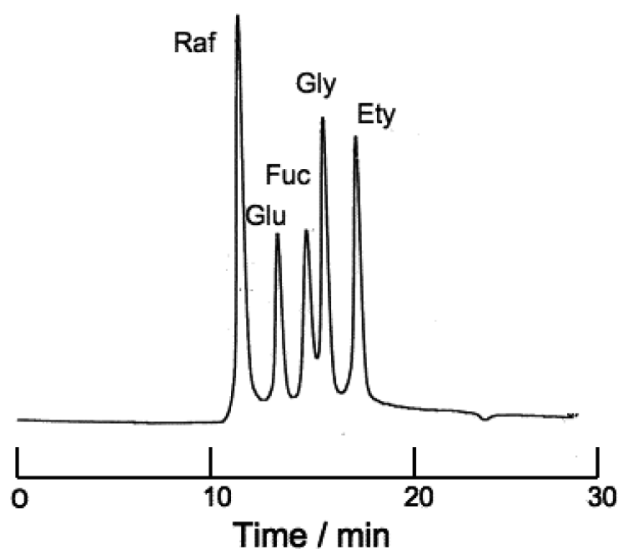

Fig. 4 HPLC separation of $20 \mathrm{nmol}$ of saccharides and alcohols. Peaks: Raf, raffinose; Fuc, fucose; Glu, glucose; Gly, glycerol; Ety, ethylene glycol.

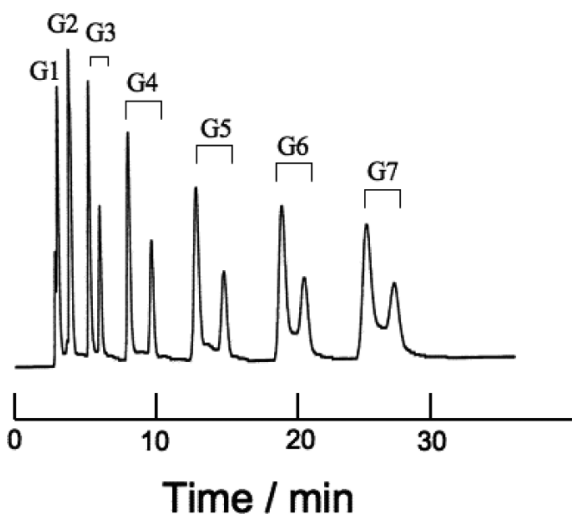

Fig. 5 HPLC separation of $5 \mathrm{nmol}$ samples of maltooligosaccharides. room temperature; detector temperature, $30.0^{\circ} \mathrm{C}$. An oxidation potential of $1.95 \mathrm{~V} \mathrm{vs.} \mathrm{Ag} / \mathrm{AgCl}$ was applied to the detector; $20 \mathrm{nmol}$ of each sample (Glu, Fuc, Raf, Gly and Ety) was injected, and the resulting chromatograms are shown in Fig. 4 , which reveal excellent separation and detection performance. The saccharides and alcohols were detected to the following limits: Glu and Fuc, $100 \mathrm{pmol}(S / N=5)$; Gly and Ety, 80 pmol $(S / N=5)$; Raf, $25 \mathrm{pmol}(S / N=5)$. Linear ranges were acquired for all of the measured compounds from the detection limits to $50 \mathrm{nmol}\left(R^{2}=>0.999\right)$. Thus, BDD detection was also successfully achieved using the HPLC system.

Maltooligosaccharides. HPLC experiments were performed on maltooligosaccharides using the following HPLC conditions:

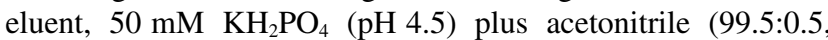
$\mathrm{v} / \mathrm{v}$ ); eluent flow rate, $1 \mathrm{~mL} / \mathrm{min}$; HPLC column, Develosil RP-Aqueous-AR at room temperature; detector temperature, $30.0^{\circ} \mathrm{C}$. An oxidation potential of $2.13 \mathrm{~V}$ vs. $\mathrm{Ag} / \mathrm{AgCl}$ was applied to the detector (the optimal oxidation potential was shifted by the addition of acetonitrile); $5 \mathrm{nmol}$ of each maltooligosaccharide sample $(\mathrm{G} 1$ - G7) was injected. Figure 5 shows the resulting chromatograms. The elution of maltooligosaccharides is dependent on the number of glucose molecules, in the order of $\mathrm{G} 1<\mathrm{G} 2<\mathrm{G} 3<\mathrm{G} 4<\mathrm{G} 5<\mathrm{G} 6<\mathrm{G} 7$. For compounds larger than $\mathrm{G} 3$, elution separates the $\alpha$ and $\beta$ forms according to the hydroxyl group at the reducing terminal of the sugar. For $\mathrm{G} 7$, the degree of $\alpha-\beta$ separation is $R_{\mathrm{s}}=1.3$. The maltooligosaccharides were detected to the following limits: G1, $50 \mathrm{pmol}(S / N=5) ; \mathrm{G} 2,50 \mathrm{pmol}(S / N=5) ; \mathrm{G} 3-\beta$, $50 \mathrm{pmol}(S / N=5)$; G4- $\beta, 50 \mathrm{pmol}(S / N=5) ; \mathrm{G} 5-\beta, 25 \mathrm{pmol}$ $(S / N=3)$; G6- $\beta, 50 \mathrm{pmol}(S / N=3)$; G7- $\beta, 50 \mathrm{pmol}(S / N=3)$. Linear ranges were acquired for all of the measured compounds from the detection limits to $50 \mathrm{nmol}\left(R^{2}=>0.996\right)$. The intra-assay reproducibility had an RSD of 3.3\% (G7, n=6) and the inter-assay reproducibility had an RSD of $7.0 \%(\mathrm{G} 7, n=3)$.

\section{Electrochemical oxidation reaction}

Sugar-related compounds can be detected with sensitivity using a BDD detector with a high applied oxidation potential. The electrochemical oxidation reaction on the electrode surface was examined next using $\mathrm{CV}$ to clarify the electrochemical oxidation reaction of sugar. For these experiments, Glu was dissolved in $100 \mathrm{mM} \mathrm{KH}_{2} \mathrm{PO}_{4}$ buffer $(\mathrm{pH} 2-10)$. CV measurements were performed at a scan rate of $100 \mathrm{mV} / \mathrm{s}$. However, the presence of an oxidation potential peak could not be confirmed; the lack of anodic and cathodic peaks in the
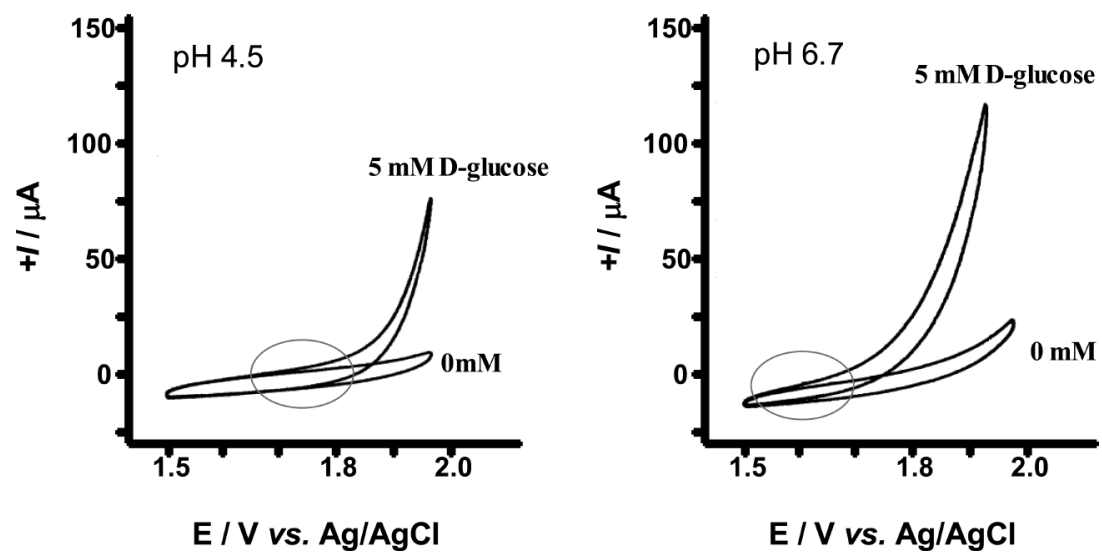

Fig. 6 CVs measured for $5 \mathrm{mM}$ glucose in a buffer solution $\left(100 \mathrm{nM} \mathrm{KH_{2 }} \mathrm{PO}_{4}\right)$ at $\mathrm{pH} 4.5$ (left) and 6.7 (right). Scan rate, $100 \mathrm{mV} / \mathrm{s}$. 


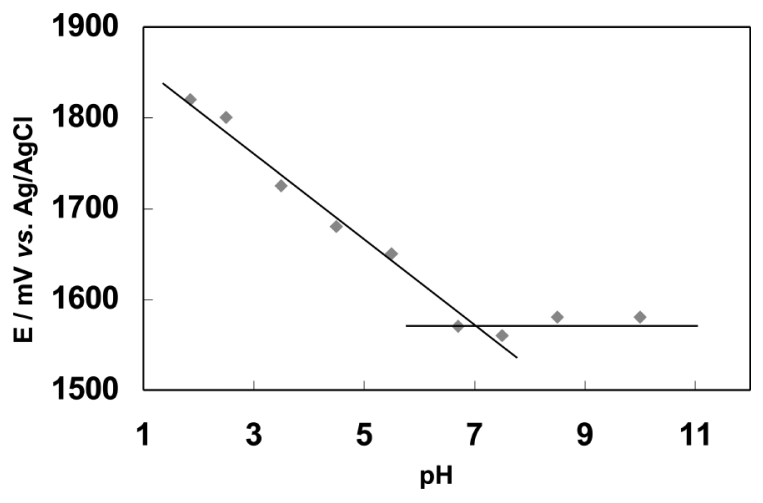

Fig. 7 Plot of the applied oxidation potential $\left(E_{\mathrm{p}}\right) v s$. $\mathrm{pH}$ for $5 \mathrm{mM}$ glucose.

potential range of $1.5-2.0 \mathrm{~V}$ vs. $\mathrm{Ag} / \mathrm{AgCl}$ indicated that the process is irreversible. The influence of the $\mathrm{pH}$ was then investigated. Figure 6 shows the effect of the $\mathrm{pH}$ on the oxidation current for a $5 \mathrm{mM}$ glucose solution adjusted to $\mathrm{pH}$ values of 4.5 and 6.7. From the point where the solutions can first be differentiated from the blank (no Glu addition), the oxidation potential shifts to the low-potential side $\mathrm{pH}$. The applied oxidation potential in this portion of the $\mathrm{CV}$ is denoted as $E_{\mathrm{p}}$. Figure 7 shows the effect of the $\mathrm{pH}$ on $E_{\mathrm{p}}$ for Glu in the $\mathrm{pH}$ range of $2-10$. In the acid portion of the $\mathrm{pH}$ range, $E_{\mathrm{p}}$ decreases linearly, whereas it remains almost constant in the alkaline portion of the range. The slope of the plot in the acid portion below the inflection point at the $\mathrm{pH} 7$ is $-57 \mathrm{mV} / \mathrm{pH}$ unit. It is expected that this result reflects the electrolysis of water. Overall consideration of the $\mathrm{CV}$ shape suggests that the reaction of Glu on the BDD-electrode surface is not a direct, but an indirect oxidation reaction. This suggests that glucose oxidation at the high applied potentials used for the BDD-electrode is related to the electrolysis of water. Electrooxidation of BDD electrodes has been considered to be an advanced oxidation process with many advantages over other known chemical processes. The BDD electrode surface allows the production of hydroxy radicals from the electrolysis of water. ${ }^{36-39}$ Experimental evidence has been provided for the generation of hydroxyl radicals on BDD electrodes using coumarin, followed by fluorescence detection of the hydroxylation product. ${ }^{37}$ Moreover, this hydroxy radical is used for the combustion of organic compounds. ${ }^{38,39}$ Therefore, hydroxy radicals are also expected to be generated on the surface of the BDD electrode in the present study; hydroxy radicals are generated by the electrolysis of water, and then indirectly oxidize glucose according to the following two-step mechanism:

$$
\begin{aligned}
& \mathrm{BDD}()+\mathrm{H}_{2} \mathrm{O} \longrightarrow \mathrm{BDD}(\cdot \mathrm{OH})+\mathrm{H}^{+}+\mathrm{e}^{-} \\
& \mathrm{BDD}(\cdot \mathrm{OH})+\mathrm{R} \longrightarrow \mathrm{BDD}(\mathrm{l})+\mathrm{RO}+\mathrm{H}^{+}+\mathrm{e}^{-}
\end{aligned}
$$

In the first step of the mechanism, hydroxy radicals are generated by the electrolysis of water on the electrode surface $\left(\mathrm{BDD}\left({ }^{\circ} \mathrm{OH}\right)\right)$. In the second step of the mechanism, $\mathrm{BDD}\left({ }^{\circ} \mathrm{OH}\right)$ reacts with glucose $(\mathrm{R})$ to form $\mathrm{RO}$ (detached from the electrode) plus a proton and electron, which is expected to cause an increase in the oxidation current. When hydroxy radicals and glucose react on the surface of the BDD electrode via several organic acids as a intermediate, the final products are expected to be $\mathrm{CO}_{2}$ and $\mathrm{H}_{2} \mathrm{O}$. The same mechanism has been reported for the oxidation of carboxylic acids and phenol at BDD electrodes. ${ }^{36,38}$ This mechanism explains why the BDD detector can detect glucose. In addition, compounds other than glucose can also react with hydroxy radicals, this detector can be useful for the detection of sugars.

\section{Conclusions}

An FIA system was constructed and equipped with a BDDelectrode detector. The system can detect sugar-related compounds with picomole level sensitivity under optimized detection conditions and with the application of a high oxidation potential $(2.00 \mathrm{~V} v s . \mathrm{Ag} / \mathrm{AgCl})$. The system exhibits increased sensitivity with increasing number of sugar molecules, as determined from experiments with maltooligosaccharides (G1 - G7). An HPLC system was also constructed, which performed equally well. Furthermore, the oxidation reaction of sugar on the BDD-electrode was examined using $\mathrm{CV}$. In a two-step mechanism, the electrolysis of water generates $\mathrm{OH}$ radicals, which then react with sugars at the BDD-electrode. Thus, a BDD detector is generally useful for the sensitive detection of sugar-related compounds, and thus is expected to find wide application.

\section{References}

1. T. Kohma, D. Oyamatsu, and S. Kuwabata, Electrochem. Commun., 2007, 9, 1012.

2. P. Du, B. Zhou, and C. Cai, J. Electroanal. Chem., 2008, $614,149$.

3. W. Jia, Y. Hu, Y. Song, K. Wang, and X. Xia, Biosens. Bioelectron., 2008, 23, 892.

4. Z. Wang, S. Liu, P. Wu, and C. Cai, Anal. Chem., 2009, 81, 1638.

5. G. Du, C. Lin, and A. B. Bocarsly, Anal. Chem., 1996, 68, 796.

6. J. Wang and L. Angnes, Anal. Chem., 1992, 64, 456.

7. D. J. Daly, C. K. O'Sullivan, and G. G. Guilbault, Talanta, 1999, 49, 667.

8. O. M. Schuvailo, O. O. Soldatkin, A. Lefebvre, R. Cespuglio, and A. P. Soldatkin, Anal. Chim. Acta, 2006, $573-574,110$.

9. R. W. Min, J. Nielsen, and J. Villadsen, Anal. Chim. Acta, 1995, 397, 149.

10. S. V. Prabhu and R. P. Baldwin, Anal. Chem., 1989, 61, 2258.

11. J. M. Zadeii, J. Marioli, and T. Kuwana, Anal. Chem., 1991, 63, 649 .

12. I.-H. Yeo and D. C. Johnson, J. Electroanal. Chem., 2001, 495, 110.

13. R. E. Reim and R. M. Van Effen, Anal. Chem., 1986, 58, 3203.

14. D. C. Johnson and W. R. LaCourse, Anal. Chem., 1990, 62, 589A.

15. W. R. LaCourse and D. C. Johnson, Carbohydr. Res., 1991, $215,159$.

16. I. G. Casella, E. Desimoni, and T. R. I. Cataldi, Anal. Chim. Acta, 1991, 248, 117.

17. S. Berchmans, H. Comathi, and G. P. Rao, J. Electroanal. Chem., 1995, 394, 267.

18. T. R. I. Cataldi, I. G. Casella, and E. Desimoni, Anal. Chim. Acta, 1992, 270, 161. 
19. S. V. Prabhu and R. P. Baldwin, Anal. Chem., 1989, 61 2258.

20. Y. Wei and M.-Y. Ding, J. Chromatogr., A, 2000, 904, 113

21. H. Mikami and Y. Ishida, Bunseki Kagaku, 1983, 32, E207.

22. Y. C. Lee, B. I. Lee, N. Tomiya, and N. Takahashi, Anal. Biochem., 1990, 188, 259.

23. S. Honda, T. Konishi, S. Suzuki, M. Takahashi, K. Kakehi, and S. Ganno, Anal. Biochem., 1983, 134, 483.

24. T. D. Schlabatch and J. Robinson, J. Chromatogr., 1983, $134,483$.

25. S. Honda, Y. Matsuda, M. Takahashi, and K. Kakehi, Anal. Chem., 1980, 52, 1079.

26. A. Fujishima, Y. Einaga, T. N. Rao, and D. A. Tryk, "Diamond Electrochemistry", 2005, Elsevier.

27. J. Lee and S.-M. Park, Anal. Chim. Acta, 2005, 545, 27.

28. T. A. Ivandini, T. N. Rao, A. Fujishima, and Y. Einaga, Anal. Chem., 2006, 78, 3467.

29. E. Popa, Y. Kubota, D. A. Tryk, and A. Fujishima, Anal. Chem., 2000, 72, 1724.

30. C. Terashima, T. N. Rao, B. V. Sarada, D. A. Tryk, and A. Fujishima, Anal. Chem., 2002, 74, 895.
31. T. A. Ivandini, B. V. Sarada, T. N. Rao, and A. Fujishima, Analyst, 2003, 128, 924.

32. T. A. Ivandini, K. Honda, T. N. Rao, A. Fujishima, and Y. Einaga, Talanta, 2007, 71, 648.

33. A. Morão, A. Lopes, M. T. Pessoa de Amorim, and I. C. Gonçalves, Electrochim. Acta, 2004, 49, 1587.

34. M. Panizza and G. Cerisola, Electrochim. Acta, 2005, 51, 191.

35. B. Marselli, J. Garcia-Gomez, P. A. Michaud, M. A. Rodrigo, and Ch. Comninellis, J. Electrochem. Soc., 2003, 150, D79.

36. J. Iniesta, P. A. Michaud, M. Panizza, G. Cerisola, A. Aldaz, and Ch. Comninellis, Electrochim. Acta, 2001, 46, 3573.

37. M. Komatsu, T. N. Rao, and A. Fujishima, Chem. Lett., 2003, 32, 396.

38. D. Gandini, E. Mahe, P. A. Michaud, W. Haenni, A. Perret, and Ch. Comninellis, J. Appl. Electrochem., 2000, 30, 1345.

39. K. Honda, Y. Yamaguchi, Y. Yamanaka, M. Yoshimatsu, Y. Fukuda, and A. Fujishima, Electrochim. Acta, 2005, 51, 588. 